\title{
Propranolol therapy for infantile hemangioma: our experience
}

This article was published in the following Dove Press journal:

Drug Design, Development and Therapy

8 May 2017

Number of times this article has been viewed

\section{Ling Zhangl,* \\ Hai-Wei Wu ${ }^{1, *}$ \\ Weien Yuan ${ }^{2}$ \\ Jia-Wei Zheng'}

'Department of Oral-Maxillary Head and Neck, Ninth People's

Hospital, College of Stomatology,

Shanghai Jiao Tong University

School of Medicine, Shanghai Key

Laboratory of Stomatology, Shanghai,

${ }^{2}$ School of Pharmacy, Shanghai Jiao

Tong University, Shanghai, People's

Republic of China

*These authors contributed equally to this work
Correspondence: jia-Wei Zheng Department of Oral-Maxillary Head and Neck, Ninth People's Hospital, College of Stomatology, Shanghai Jiao Tong University School of Medicine, 639 Zhi Zao Ju Road, Shanghai 2000II, People's Republic of China

Tel $+86212327 \quad 063$

Fax +86 2I 63I2 I780

Email zhjw@omschina.org.cn

Weien Yuan

School of Pharmacy, Shanghai Jiao Tong

University, No 800, Dongchuan

Road, Shanghai 200240, People's

Republic of China

Email yuanweien@I26.com
Objective: Hemangiomas are the most common benign vascular tumors of infancy. Although most infantile hemangiomas (IHs) have the ability to involute spontaneously after initial proliferation and resolve without consequence, intervention is required in a subset of IHs, which develop complications resulting in ulceration, bleeding, or aesthetic deformity. The primary treatment for this subset of IHs is pharmacological intervention, and propranolol has become the new first-line treatment for complicated hemangiomas. Here, we evaluated the efficacy of propranolol on proliferation IH in a clinical cohort including 578 patients.

Methods: We retrospectively reviewed a total of $578 \mathrm{IH}$ patients who were treated with oral propranolol from January 2010 to December 2012. Responses to the propranolol treatment were graded as: excellent, good, poor, or no response. Based on the response to propranolol treatment (once daily at a dose of $1.0 \mathrm{mg} / \mathrm{kg}$ for patients younger than 2 months; twice daily at daily total dose of $2 \mathrm{mg} / \mathrm{kg}$ for patients older than 2 months), additional pharmacotherapies or surgery were used for IH patients for satisfactory clinical outcome.

Results: Five hundred and sixty $(96.9 \%)$ of $578 \mathrm{IH}$ patients in our study responded to oral propranolol treatment, and the response rate was significantly different for different ages of patients $(P<0.05)$, with the youngest patients having the highest response rate. The mean time of treatment was 6 months (range, 3-12 months). For example, response rate to propranolol was $98.1 \%$ in patients younger than 2 months, compared with $93.3 \%$ in patients older than 2 months and younger than 8 months, and $73.7 \%$ in patients older than 8 months. One hundred and thirty one patients who exhibited incompletely involuted hemangiomas were further treated with timolol maleate $(n=89)$ or pulsed dye laser $(n=42)$. One hundred and seventeen $(89.3 \%)$ of 131 patients showed a positive response. There were no instances of life-threatening complications after propranolol. However, minor side effects were observed including 10 (1.73\%) cases of sleep disturbance, 7 (1.21\%) cases of diarrhea, and $5(0.86 \%)$ cases of bronchospasm.

Conclusion: IH requires early intervention. During the involution phase, tapering propranolol dosage can be done to minimize side effects before discontinuing treatment. For patients exhibiting telangiectasia and chromatosis after propranolol treatment, administration of a $0.5 \%$ solution of timolol maleate or pulse dye laser is an effective therapeutic approach for complete involution.

Keywords: propranolol, infantile hemangioma, $\beta$-blockers, oral propranolol, intervention studies

\section{Introduction}

Infantile hemangiomas (IHs) are the most common benign tumor in pediatric patients, and $60 \%$ of IHs occur on the head and neck. ${ }^{1}$ The natural history of IH is characterized by a rapid proliferative phase during early infancy, from birth to approximately 1 year of age, followed by a gradual involution that may last until the age of 10 years. ${ }^{2}$ Previous treatment of IH commonly involved implementing a "watch-and-wait" 
strategy. However, a subset of IHs cannot involute spontaneously and this may lead to unpredictable outcome, including serious complications and cosmetic disfigurement, causing functional and psychological effects on parents and the affected children. ${ }^{3}$ Therefore, there is an urgent need for prompt recognition and treatment for this IH subset. ${ }^{4}$ Traditional therapy for IH includes long-term and high-dose usage of steroids, which has been reported to be associated with multiple side effects. ${ }^{5}$ In 2008 , Léauté-Labrèze et $\mathrm{al}^{6}$ found propranolol as a treatment for severe hemangiomas of infancy by accident. The $\beta$-blocker has become the new first-line treatment for complicated hemangiomas. ${ }^{6}$ However, the efficacy of propranolol in treating IH patients is not universal. For patients resistant to propranolol therapy, there are other options including oral administration of prednisone and intraregional injections of pingyangmycin, interferon $\alpha$ (IFN- $\alpha$ ), or vincristine. ${ }^{7-10}$ These treatments all have potentially severe side effects. Topical use of timolol in IH patients can help avoid side effects of propranolol treatment. ${ }^{11}$ Further studies are required to improve the efficacy and reduce side effects of current IH therapies. In this study, we describe the results of treating IH patients with propranolol only or propranolol followed by prednisone, timolol, or pulsed dye laser, which contributes to the practice guideline for the treatment of patients with $\mathrm{IH}$.

\section{Methods}

\section{Patients}

This study enrolled 578 patients undergoing treatment for $\mathrm{IH}$ at the Ninth People's Hospital, Shanghai Jiao Tong University School of Medicine, People's Republic of China, from January 2010 to December 2012. The human subject protocol was approved by the Ethics Committee of the Ninth People's Hospital (IRB:201548). Patients were diagnosed with proliferating IH by the Department of Oral-Maxillary Head and Neck at the Ninth People's Hospital Shanghai and written informed consents were obtained from the parents or guardians including images to be published for this study in accordance with The World Medical Association Declaration of Helsinki. A standardized database recorded patient details, which included patient gender, age at treatment initiation, location and size of the lesion, medication and dose, clinical response, and complications resulting from treatment and follow-up.

\section{Propranolol treatment}

Prior to propranolol treatment, a color sonography was performed to detect any possible congenital cardiac disturbances such as atrioventricular block or bradycardia etc. For propranolol treatment, patients were treated on an outpatient basis, and the mean time of treatment was 6 months. To minimize complications, oral propranolol was administered once daily at a dose of $1.0 \mathrm{mg} / \mathrm{kg}$ for patients younger than 2 months, while it was administered twice daily at daily total dose of $2 \mathrm{mg} / \mathrm{kg}$ for patients older than 2 months. In the last month of treatment, the propranolol dose was halved for the first 2 weeks. If no rebound occurred, the dose was further halved for the following 2 weeks before propranolol treatment was discontinued completely. Patient body weight was measured every 2 weeks and propranolol dosage was adjusted according to the change of body weight.

\section{Advanced treatments}

For patients with small tumor reduction after treatment with propranolol for 2 weeks, oral prednisone was administered at a dose of $5 \mathrm{mg}$ every 2 days.

For patients with complicated hemangiomas and those nonresponsive to propranolol or prednisone treatment, pingyangmycin, IFN- $\alpha$, or vincristine treatments were applied. These three medicines were used only in the second or third line owing to the potential side effects. For pingyangmycin treatment, patients were intralesionally injected a daily dose of $1 \mathrm{mg}$ for 2.5 months. For IFN- $\alpha$ treatment, patients were subcutaneously injected a daily dose of $3 \times 10^{6} \mathrm{Unit} / \mathrm{m}^{2}$ for 3 months. For vincristine treatment, patients were intravenously administered a dose of $1.0 \mathrm{mg} / \mathrm{m}^{2}$ every 2 weeks with an interval of 1 week between rounds and a total of 2 rounds.

For patients with chromatosis or telangiectasia after propranolol treatment, a $0.5 \%$ solution of timolol maleate was applied topically over the lesion surface using a cotton swab 3 times daily. If no response was observed after 2 weeks of treatment with timolol maleate, high-frequency pulsed dye laser was applied using a wavelength of $595 \mathrm{~nm}$ and a pulse duration of $10 \mathrm{~ms}$.

\section{Therapy evaluation}

Photographs were taken and ultrasound examinations were done to evaluate therapy efficacy. Ultrasound examination can measure the width and the height of IH lesions. Volume $=$ width $\times$ height ${ }^{2} / 2 .{ }^{12}$ Both photographs and ultrasound examinations were performed prior to treatment, at 2 weeks, 1 month, and 3 months following treatment as well as at each follow-up visit. Photographs can enable direct visualization of volume change, and ultrasound examinations can provide the quantitative data. Responses to propranolol were graded as follows: a tumor reduction greater than 
$75 \%$ was considered an "excellent" response; a reduction greater than $50 \%$ a "good" response; a reduction of $25 \%$ or less a "poor" response; and a $0 \%$ reduction was considered "nonresponsive."

\section{Statistical analysis}

Response rate (RR) to propranolol was summarized according to patient demographic or disease characteristics using analysis of paired $t$-test, with $P<0.05$ considered significant. Software SPSS (Version 19.0; IBM Corporation, Armonk, NY, USA) was used to perform the statistical analysis.

\section{Results}

\section{Patient demographic and disease characteristics}

This study was conducted in a cohort of 578 patients with mean age of $6.12 \pm 5.29$ months (range, 1-12 months). The overall male-to-female ratio was 1:4.7. Ninety seven $(16.8 \%)$ of 578 patients were premature, and progesterone was the most common tocolytic agent used for the treatment of mothers during the gestational period. The most common anatomic sites in this study were lips $(17.5 \%)$ and the eyelids (15.4\%) (Figure 1). The mean size of hemangioma was $20.26 \pm 19.57 \mathrm{~cm}^{2}$. Five hundred and twenty nine $(91.5 \%)$ hemangiomas were superficial hemangiomas, 38 (6.6\%) were subcutaneous hemangiomas, and 11 (1.7\%) were mixed hemangiomas.

\section{Patient response to propranolol treatment}

Our results revealed significant differences in RR for different ages of patients, with the youngest patients having the highest RR $(P<0.05, t$-test $) . R R$ to propranolol in the group younger than 2 months was $98.1 \%$ (Figure 2), compared with $93.3 \%$ in patients older than 2 months and younger

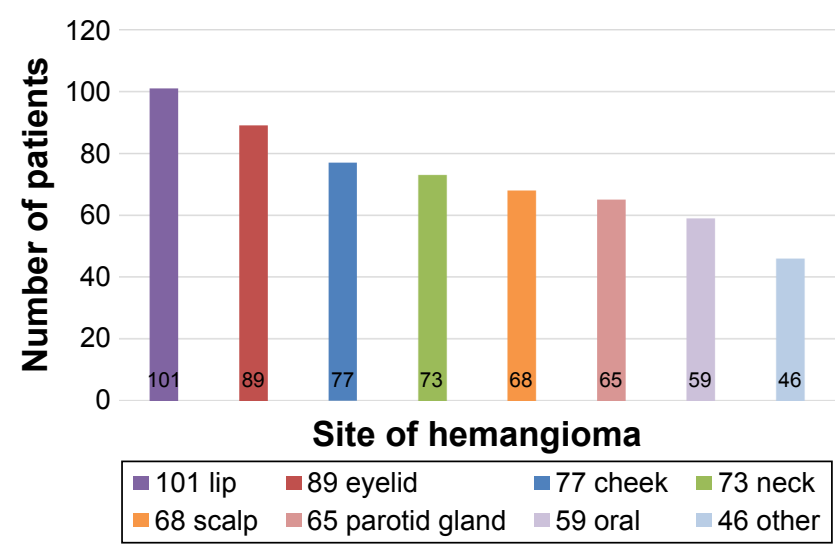

Figure I The anatomic site of hemangiomas in this study. than 8 months (Figures 3 and 4), and 73.7\% in patients older than 8 months (Figure 5). The difference was not related to gender. In addition, as for the tumor location, RR was highest when tumors were located in the parotid region and lowest in the lip region (RR: $97.8 \%, 85.1 \%, P<0.05$, $t$-test). However, RR to propranolol was not significant for different types of IH (superficial, subcutaneous, or mixed hemangiomas RR: $94.5 \%, 91.7 \%$ vs $87.3 \%, P<0.05$, $t$-test). Moreover, RR to propranolol was further characterized as follows: $186(32.2 \%)$ of 578 patients exhibited excellent response; 317 (54.8\%) exhibited good response; 57 (9.9\%) exhibited poor response; and 18 (3.1\%) were nonresponsive. The mean time of treatment was 6 months (range, 3-12 months) (Figure 6).

\section{Patient response to advanced treatments}

For patients with poor response or those who were nonresponsive to propranolol (75 patients), oral prednisone was added to the treatment regimen. After treatment with prednisone, lesions in $67(89.3 \%)$ of 75 patients involuted without rebound. As for the remaining 8 nonresponsive patients, advanced treatments were administered including pingyangmycin ( 2 patients), IFN- $\alpha$ (1 patient), vincristine ( 2 patients), or surgical intervention (3 patients). No rebound was observed in these 8 cases, and patients all showed satisfactory results to advanced treatments.

After propranolol treatment, 131 patients exhibited incompletely involuted hemangiomas (chromatosis or telangiectasia) and were further treated with timolol maleate (89 patients) (Figure 7) or pulsed dye laser (42 patients). One hundred and seventeen $(89.3 \%)$ of 131 patients showed positive response.

Overall, no patients in our study developed lifethreatening complications; 23 (3.98\%) of 578 patients developed minor complications including sleep disturbance (10 patients), diarrhea (7 patients), and bronchospasm (5 patients). The mean duration of follow-up was $3.08 \pm 0.83$ years (Figures $2-5$ and 7 ). For patients with excellent (186 patients) or good propranolol response (317 patients), rebounds of IHs were only detected in $6(1.2 \%)$ of 503 patients, which faded away with additional propranolol treatment for no more than 3 months.

\section{Discussion}

Currently, there is no way to predict the outcome of proliferative $\mathrm{IH} .{ }^{13}$ A subset of $\mathrm{IH}$ can potentially be associated with psychological trauma of infants and anxiety of parents, which requires early intervention, thus calling for the reevaluation of traditional "watch and wait" approaches 

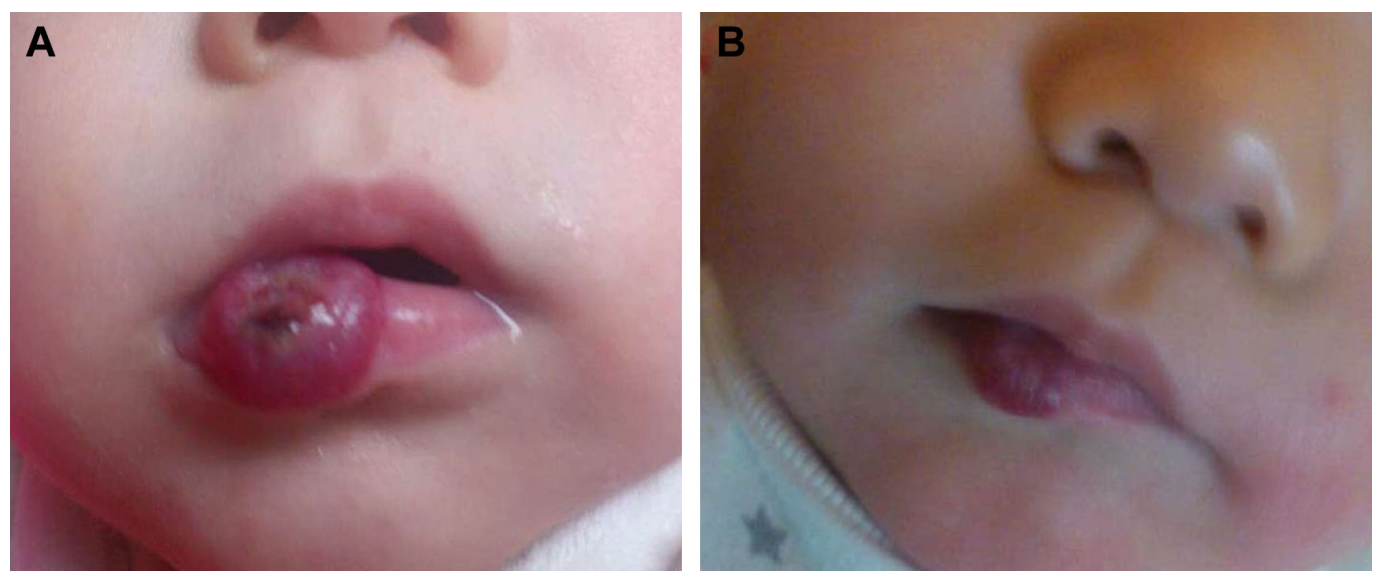

Figure 2 (A) A 2-month-old female patient had a large hemangioma located on her right lower lip which showed ulceration on its surface. (B) The hemangioma on the same patient significantly improved after 5 -month treatment of oral propranolol.
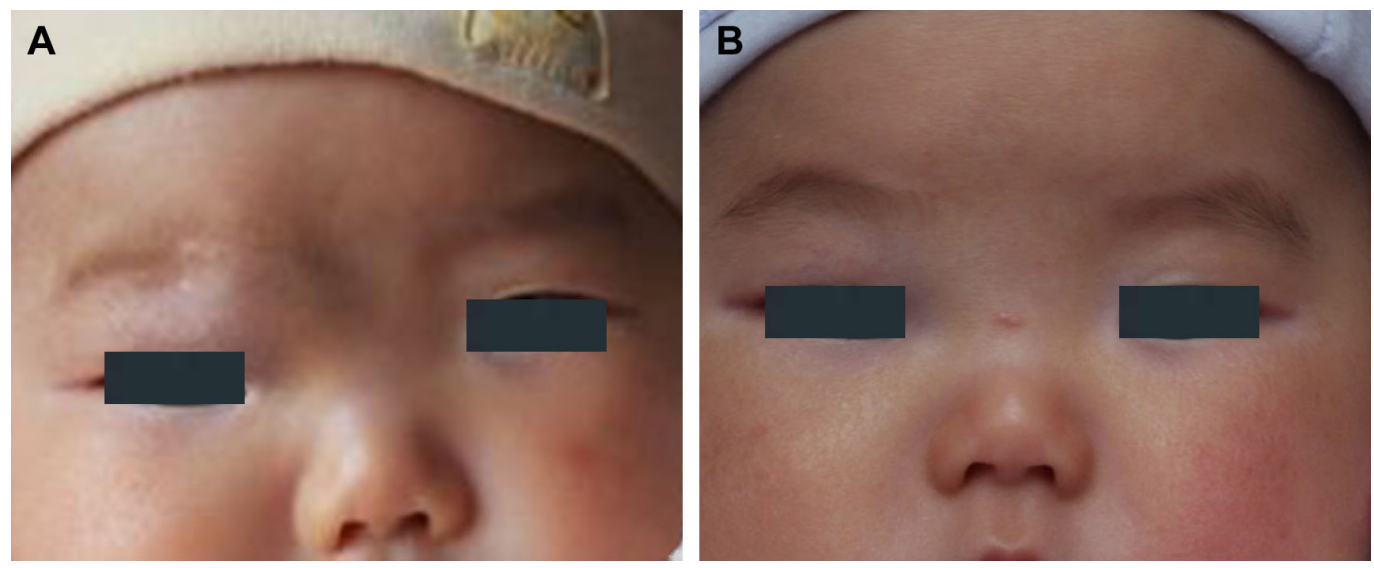

Figure 3 (A) A 3-month-old female patient with a hemangioma located on her right endocanthion. (B) The same patient with the treatment of oral propranolol for 3 months exhibited involuted hemangioma.
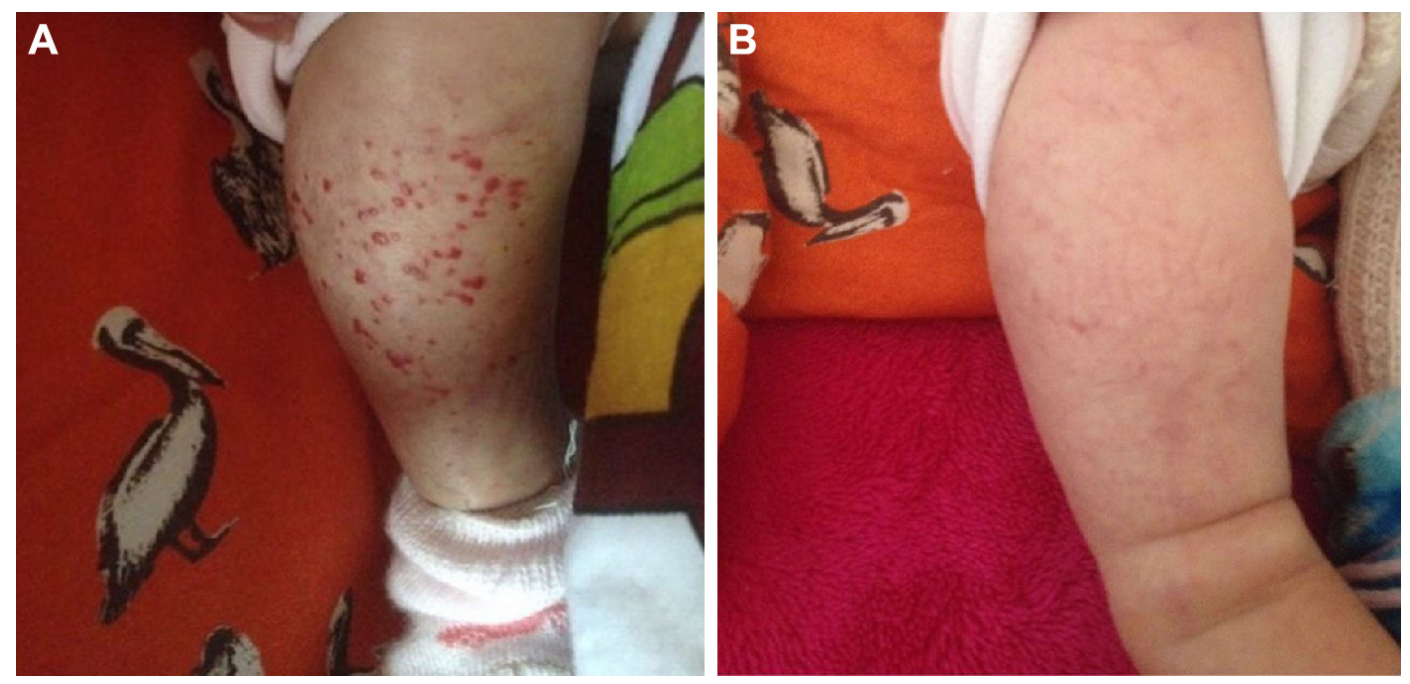

Figure 4 (A) An 8-month-old female patient with a hemangioma located on her right leg. (B) The hemangioma on the same patient involuted after 4-months treatment of oral propranolol. 

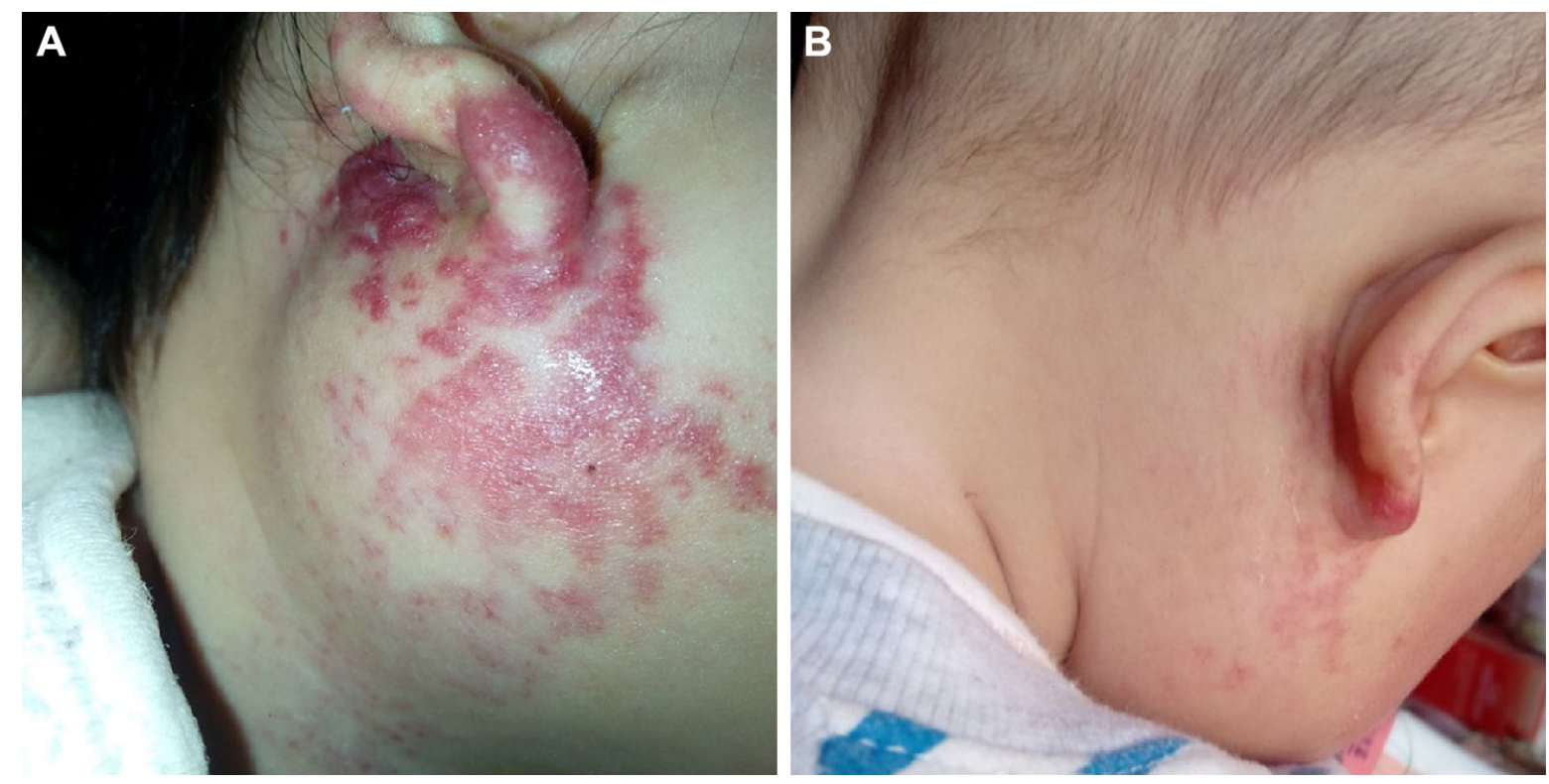

Figure 5 (A) An II-month-old female patient with a hemangioma located on the right parotid region. (B) The hemangioma on the same patient involuted after 4-month treatment of oral propranolol.

for IH treatment. ${ }^{14}$ So far, different modalities have been reported for the treatment of IHs, including surgery (laser surgery and cryosurgery) and pharmacotherapy ( $\beta$-blocker, corticosteroids, INF- $\alpha$, and vincristine). As a $\beta$-blocker, propranolol has been proven to be very effective and safe for IH therapy, which dramatically changes IH therapeutic strategy and makes propranolol replace corticosteroids as the first-line treatment for $\mathrm{IH}^{15}$

Although no standard regimen for IHs has been established, treatment of IH should be taken carefully and instituted with rigorous guidelines. In previous studies, we treated $\mathrm{IH}$ patients

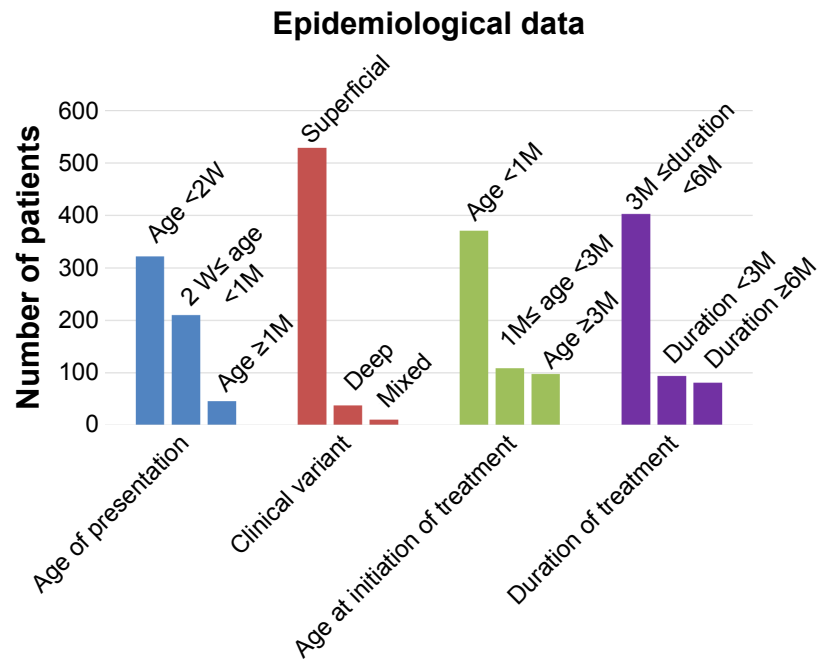

Figure 6 Patient demographic and disease characteristics. Abbreviations: $M$, month; $W$, week. with oral propranolol as inpatients for 48 hours and closely monitored their blood pressure and heart rates. No obvious changes were observed. In this study, IH patients were treated with oral propranolol in an outpatient setting. The dose was not unique because the potential side effects were not clear. So we initiated propranolol therapy at a dose of $1-2 \mathrm{mg} / \mathrm{kg} / \mathrm{d}$, and then tapered propranolol over a 1-month period to minimize the risk of withdrawal response. In addition, oral propranolol was administered after food to reduce the risk of hypoglycemia. The remarkable efficacy of propranolol for the treatment of $\mathrm{IH}$ was observed not only in the rapid growth phase but also in the following involution phase. ${ }^{16}$ Therefore, the duration of propranolol treatment for IH patients is also very important for clinical outcome. In this study, the duration of propranolol therapy lasted an average of 6 months, and treatment was terminated when the infants reached 1 year of age. ${ }^{17}$

The efficacy of propranolol on our IH patient cohort was encouraging, with good RR, few rebounds, and limited side effects. All $\mathrm{IH}$ patients receiving advanced treatment exhibited satisfactory outcome. ${ }^{18}$ For patients with excellent or good response to propranolol, 131 (26\%) exhibited telangiectasia and chromatosis after treatment and were further treated with a $0.5 \%$ solution of timolol maleate or pulsed dye laser for complete involution. ${ }^{19}$ Timolol is a $\beta$-blocker and commonly used to treat nasal telangiectasia and epistaxis. ${ }^{20}$ Timolol also plays a critical role in the treatment of superficial $\mathrm{IH} .{ }^{21}$ Compared with systemic oral propranolol treatment, 

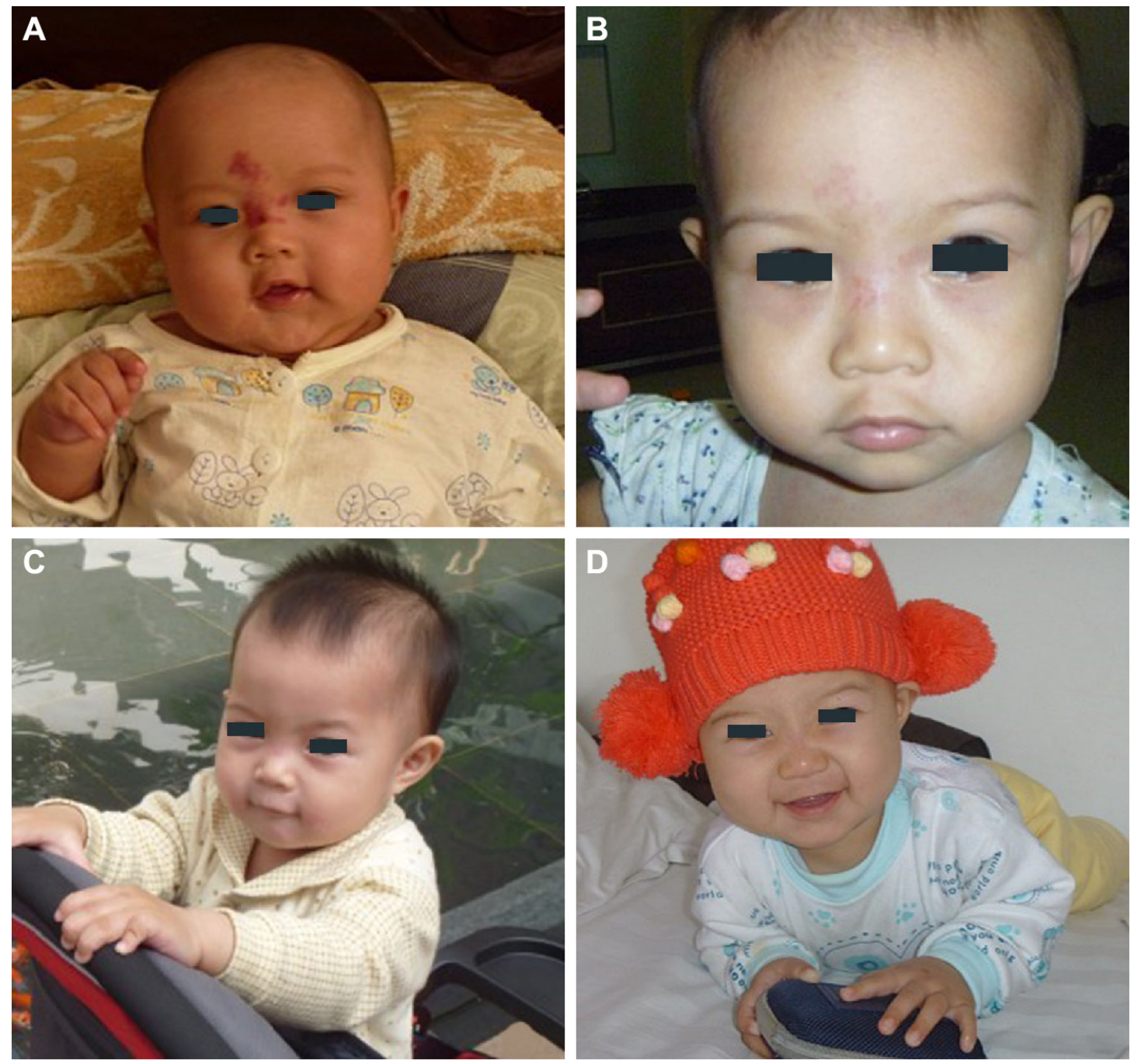

Figure 7 (A) A 6-month-old male patient with a hemangioma located on his nasion and forehead. (B) After 6-month treatment of oral propranolol, the same patient exhibited involuted hemangioma with telangiectasia and chromatosis remaining on his nasion and forehead. (C) The telangiectasia and chromatosis on the same patient improved significantly after treatment with a $0.5 \%$ solution of timolol maleate for 8 weeks. Two drops of $0.5 \%$ timolol maleate solution was applied onto the surface of the hemangioma three times daily. (D) The telangiectasia and chromatosis were involuted completely after 24 months.

topical timolol treatment is nonsystemic and associated with less side effects. ${ }^{22-24}$

Despite the success of propranolol in IH treatment, the underlying mechanism of propranolol treatment remains elusive. A previous study demonstrated that propranolol targets hemangioma stem cells via cAMP and mitogen-activated protein kinase regulation. ${ }^{25}$ In this study, we found that RR to propranolol was significantly higher in younger patients, with patients younger than 2 months having the highest RR, which is in line with previous findings. We think estrogen is the critical factor. In our basic research, at the same time, we found that estrogen promoted angiogenesis via combined with $E R \alpha$ to upregulating the expression of VEGF-A in hemangioma derived stem cell, promoting proliferation of IHs. Propranolol inhibits angiogenesis via downregulating the expression of
VEGF in hemangioma-derived stem cells. ${ }^{26}$ In this study when the patient was younger, the activity was stronger. So, a better result was achieved when the patients were younger than 2 months. However, further studies are required to better clarify the mechanism of propranolol in IH treatment.

\section{Conclusion}

Early intervention is critical in treating IH. Treatment of IH with propranolol in this study demonstrated high efficacy and tolerance with few adverse effects. For patients with telangiectasia and chromatosis after propranolol treatment, administration of a $0.5 \%$ solution of timolol maleate or pulsed dye laser led to adequate involution. In cases with poor response or those who were nonresponsive to propranolol, additional surgeries or pharmacotherapies using prednisone, IFN- $\alpha$, or vincristine can 


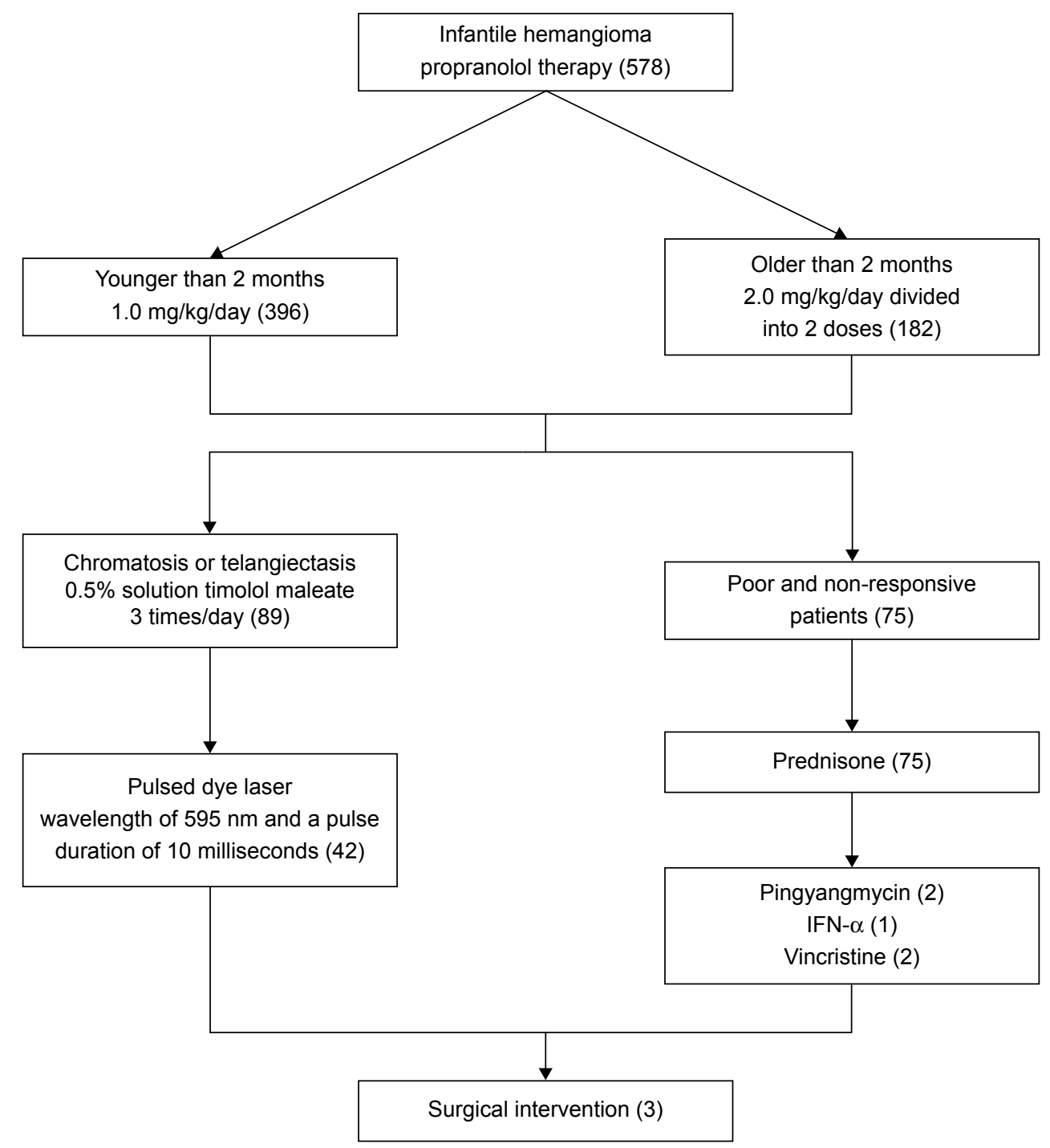

Figure 8 Treatment flow chart for patients with infantile hemangiomas in our study. Abbreviations: IFN, interferon; $\mathrm{IH}$, infantile hemangioma.

achieve satisfactory results. In summary, our study reported a successful treatment of IH using first-line treatment, advanced treatment, reevaluation, and modification of treatment according to patient response (Figure 8).

\section{Acknowledgment}

This study was supported by the National Natural Science Foundation of China (81541041) and (81570992) and the Fund for Interdisciplinary Projects of Medicine and Engineering by Shanghai Jiao Tong University (YG2015MS06).

\section{Author contributions}

All authors contributed toward data analysis, drafting and critically revising the paper and agree to be accountable for all aspects of the work.

\section{Disclosure}

The authors report no conflicts of interest in this work.

\section{References}

1. Finn MC, Glowacki J, Mulliken JB. Congenital vascular lesions: clinical application of a new classification. J Pediatr Surg. 1983;18:894-900.

2. Marler JJ, Mulliken JB. Current management of hemangiomas and vascular malformations. Clin Plast Surg. 2005;32:99-116.

3. Talaat AA, Elbasiouny MS, Elgendy DS, Elwakil TF. Propranolol treatment of infantile hemangioma: clinical and radiologic evaluations. J Pediatr Surg. 2012;47:707-714.

4. Mulliken JB, Glowachi J. Haemangiomas and vascular malformations in infants and children: a classification based on endothelial characteristics. Plast Reconstr Surg. 1983;69:412-422.

5. Fawcett SL, Grant I, Hall PN, Kelsall AWR, Nicholson JC. Vincristine as a treatment for a large haemangioma threatening vital functions. Br Assoc Plast Surg. 2004;57:168-171.

6. Léauté-Labrèze C, Dumas de la Roque E, Hubiche T, Boralevi F, Thambo JB, Taïeb A. Propranolol for severe hemangiomas of infancy. $N$ Engl $J$ Med. 2008;358:2649-2651. 
7. Hou J, Wang M, Tang H, Wang Y, Huang H. Pingyangmycin sclerotherapy for infantile hemangiomas in oral and maxillofacial regions: an evaluation of 66 consecutive patients. Int J Oral Maxillofac Surg. 2011;40:1246-1251.

8. Enjolras O, Riche MC, Merland JJ, Escande JP. Management of alarming hemangiomas in infancy: a review of 25 cases. Pediatrics. 1990;85: 491-498.

9. Ezekowitz RA, Mulliken JB, Folkman J. Interferon alfa-2a therapy for life-threatening hemangiomas of infancy. N Engl J Med. 1992;326: 1456-1463.

10. Fuchimoto Y, Morikawa N, Kuroda T, et al. Vincristine, actinomycin D, cyclophosphamide chemotherapy resolves Kasabach-Merritt syndrome resistant to conventional therapies. Pediatr Int. 2012;54(2):285-287.

11. Guo S, Ni N. Topical treatment for capillary hemangioma of the eyelid using beta blocker solution. Arch Ophthalmol. 2010;128:255-256.

12. Ortaldo JR, Porter HR, Miller P, Stevenson HC, Ozols RF, Hamilton TC. Adoptive cellular immunotherapy of human ovarian carcinoma xenografts in nude mice. Cancer Res. 1986;46:4414-4419.

13. Werner JA, Dunne AA, Folz BJ, et al. Current concepts in the classification, diagnosis and treatment of hemangiomas and vascular malformations of the head and neck. Eur Arch Otorhinolaryngol. 2001;258: 141-149.

14. Kushner BJ. Hemangiomas. Arch Ophthalmol. 2000;118:835-836.

15. Léauté-Labrèze C, Voisard JJ, Moore N. Oral propranolol for infantile hemangioma. N Engl J Med. 2015;16:284-285.

16. Chen TS, Eichenfield LF, Friedlander SF. Infantile hemangiomas: an update on pathogenesis and therapy. Pediatrics. 2013;131:99-108.

17. Zheng JW, Yang XJ, Wang YA, He Y, Ye WM, Zhang ZY. Intralesional injection of Pingyangmycin for vascular malformations in oral and maxillofacial regions: an evaluation of 297 consecutive patients. Oral Oncol. 2009;45:872-876.
18. Wang Z, Li K, Yao W, et al. Steroid-resistant kaposiform hemangioendothelioma: a retrospective study of 37 patients treated with vincristine and long-term follow-up. Pediatr Blood Cancer. 2015;62(4):577-580.

19. Moore A, Pinkerton R. Vincristine: can its therapeutic index be enhanced? Pediatr Blood Cancer. 2009;53:1180-1187.

20. Sommers Smith SK, Smith DM. Beta blockade induces apoptosis in cultured capillary endothelial cells. In Vitro Cell Dev Biol Anim. 2002;38:298-304.

21. Pope E, Chakkittakandiyil A. Topical timolol gel for infantile hemangiomas: a pilot study. Arch Dermatol. 2010;146:564-565.

22. Ge J, Zheng J, Zhang L, et al. Oral propranolol combined with topical timolol for compound infantile hemangiomas: a retrospective study. Sci Rep. 2016;6:19765.

23. Zhang L, Yuan W, Zheng J. Pharmacological therapies for infantile hemangiomas: A clinical study in 853 consecutive patients using a standard treatment algorithm. Sci Rep. 2016;6:21670.

24. Chen Z, Zheng J, Yuan M, et al. A novel topical nano-propranolol for treatment of infantile hemangiomas. Nanomedicine: NBM. 2015;11(5):1109-1115.

25. Munabi NC, England RW, Edwards AK, et al. Propranolol targets hemangioma stem cells via cAMP and mitogen-activated protein kinase regulation. Stem Cells Transl Med. 2016;5:45-55.

26. Zhang L, Mai HM, Zheng Jing, et al. Propranolol inhibits angiogenesis via down-regulating the expression of vascular endothelial growth factor in hemangioma derived stem cell. Int J Clin Exp Pathol. 2014;7:48-55.
Drug Design, Development and Therapy

\section{Publish your work in this journal}

Drug Design, Development and Therapy is an international, peerreviewed open-access journal that spans the spectrum of drug design and development through to clinical applications. Clinical outcomes, patient safety, and programs for the development and effective, safe, and sustained use of medicines are the features of the journal, which

\section{Dovepress}

has also been accepted for indexing on PubMed Central. The manuscript management system is completely online and includes a very quick and fair peer-review system, which is all easy to use. Visit http://www.dovepress.com/testimonials.php to read real quotes from published authors. 